\title{
Knowledge Generation and Field Reproduction in Temporary Clusters and the Role of Business Conferences
}

\author{
Sebastian Henn \& Harald Bathelt \\ Version Post-print/accepted manuscript \\ Citation Henn, S., \& Bathelt, H. (2015). Knowledge generation and field \\ (published version) reproduction in temporary clusters and the role of business conferences. \\ Geoforum, 58, 104-113. \\ Copyright / License C 2011. This manuscript version is made available under the CC-BY- \\ NC-ND 4.0 license. \\ http://creativecommons.org/licenses/by-nc-nd/4.0/ \\ Publisher's Statement The version of record [Henn, S., \& Bathelt, H. (2015). Knowledge \\ generation and field reproduction in temporary clusters and the role of \\ business conferences. Geoforum, 58, 104-113.] is available online at: \\ http://www.sciencedirect.com/science/article/pii/S0016718514002310 \\ [doi: 10.1016/j.geoforum.2014.10.015]
}

How to cite TSpace items

Always cite the published version, so the author(s) will receive recognition through services that track citation counts, e.g. Scopus. If you need to cite the page number of the TSpace version (original manuscript or accepted manuscript) because you cannot access the published version, then cite the TSpace version in addition to the published version using the permanent URI (handle) found on the record page. 


\title{
Knowledge Generation and Field Reproduction in Temporary Clusters and the Role of Business Conferences
}

\author{
Sebastian Henn \\ University of Jena, Institute for Geography, \\ Löbdergraben 32, 07743 Jena, Germany; \\ E-mail: sebastian.henn@uni-jena.de,URL:http://www.sebastian-henn.com \\ and \\ Harald Bathelt \\ University of Toronto, Department of Political Science \\ and Department of Geography \& Program in Planning, \\ Sidney Smith Hall, 100 St. George Street, Toronto ON M5S 3G3, Canada; \\ E-mail: harald.bathelt@utoronto.ca, URL: http://www.harald-bathelt.com
}




\begin{abstract}
This paper discusses the role of business conferences in enabling processes of knowledge transfers over distance. It argues that conferences form a specific type of temporary cluster bringing together knowing communities from crossindustry, functional fields and creating opportunities for diverse knowledge exchanges. In contrast to other types of temporary clusters, such as trade fairs, horizontal interactions with peers and competitors are at the core of business conferences, focused around presentations and keynote speeches that provide crucial reference points. Although some conferences may have a distinct field-configuring potential related to the activities of the conference organizers, the actual outcomes are mostly less predictable and depend on the diverse goals, needs and experiences of the participants. As such, conferences enable ongoing field reproduction, rather than discontinuous field configuration. This is illustrated in an explorative study of three business conferences in Toronto.
\end{abstract}

Keywords: Business conferences; field-configuring events; field reproduction; knowledge generation; temporary clusters

\title{
1. Introduction
}

Since the 2000s, a growing number of economic geographers have discussed the relevance of face-to-face communication and associated processes of knowledge generation in temporary and/or periodic settings (e.g. Norcliffe and Rendace 2003; Grabher 2004; Maskell et al. 2006; Asheim et al. 2007; Power and Jansson 2008; Grabher and Ibert 2011). In applying the concept of the 'temporary cluster' (Maskell et al. 2006), empirical studies have, for instance, investigated the role of international trade fairs in long-distance knowledge transfers (e.g. Bathelt and Schuldt 2008; Rinallo and Golfetto 2011). International business conferences, another form of global community gatherings involving representatives of firms and related organizations (Bathelt and Henn 2014), have been widely neglected in this discussion. This comes as a surprise since conferences, just like trade fairs, can be considered as short-lived professional get-togethers characterized by intensive exchanges of knowledge and the generation of new ideas relevant to a certain industry or organizational field (DiMaggio and Powell 1983; Scott 1994). ${ }^{1}$ As indicated by the growing number of meetings and events at different spatial levels (e.g. Davidson and Rogers 2006; Schlentrich 2008; ICCA 2012a), face-to-face communication with leading-edge partners and rivals from different parts of the world still plays an important role in many industries despite the decreasing costs of advanced information and communication technologies.

This paper argues that business conferences are crucial events in processes of economic knowledge creation and dissemination as they enable firms from specific organizational fields or sub-fields to connect with industrial and technological communities across geographic space. Such a perspective extends conventional research on conferences (Hansen 2010; Ravn and Elsborg 2011), which has widely neglected aspects of knowledge generation and dissemination. Only recently, scholars such as Oliver and Montgomery (2008), Hardy and Maguire (2010) or Zilber (2011) have contributed to broadening the literature in this direction by suggesting that these events have a "substantive impact ... on the evolution of [their underlying] fields" (Lampel and Meyer 2008: 1028). Corresponding processes of field-configuration may be expected at specific conferences that are hierarchically-planned and oriented towards specific goals. Based

\footnotetext{
${ }^{1}$ Here, we refer to "a recognized area of institutional life [in a specific industry or technology context, consisting of] key suppliers, resource and product consumers, regulatory agencies, and other organizations that produce similar services or products" (DiMaggio and Powell 1983: 148). Organizational fields can also be defined for different contexts, such as policy.
} 
on an explorative case study of three diverse business conferences in Toronto, we argue, however, that most conferences do not meet these conditions. Rather, they are characterized by myriads of often unplanned, decentralized knowledge flows around a common theme or business focus. Since the concept of the 'temporary cluster' focuses on knowledge flows and interactions during such events, it provides a well-suited basis to investigate the nature of conferences and to analyze how they affect a specific organizational field or parts thereof. Taking this as a starting point, the agenda of this paper is to explore how business conferences trigger specific forms of knowledge exchange and how they affect the dynamics of their underlying fields. We illustrate that business conferences establish a specific type of temporary cluster with field-reproducing rather than field-configuring consequences.

Our paper is structured as follows: Sections 2 and 3 discuss the concepts of 'fieldconfiguring events' and 'temporary clusters' with respect to business conferences. Section 4 describes the research design and methodology, before the results of our investigation of three conferences in Toronto are presented in section 5 . We conclude in section 6 , suggesting that conferences should be viewed as events that are characterized by a multitude of decentralized knowledge flows that allow for the ongoing, often gradual reproduction of an industry's institutional basis, rather than contributing to planned, discontinuous configurations of fields.

\section{Field Configuration or Reproduction?}

While not much reflected in economic geography, an established literature on conferences ${ }^{2}$ exists that focuses on aspects of site selection (e.g. Kim et al. 2010), economic impacts (e.g. Grado et al. 1997; Randall and Warf 1996), destination marketing (e.g. Simerly 1990; Davidson and Rogers 2006), the meeting participation process (e.g. Oppermann and Chon 1997; Zhang et al. 2007) and advances in technology (e.g. West and Upchurch 2001; Davidson et al. 2002). ${ }^{3}$ Even though it has been stressed that conferences establish important nodes in the global knowledge-based economy (Rogers 2008; Schlentrich 2008), research on how these events contribute to wider processes of knowledge generation and learning has been almost "nonexistent in the current scientific landscape" (Hansen 2010: 28), and has only recently been picked up (Hansen 2010; Ravn and Elsborg 2011).

Related to this, a small but growing number of authors have applied the concept of 'fieldconfiguring events (FCEs)' to conferences thereby investigating how they shape and configure specific fields (e.g. Meyer et al. 2005; Garud 2008; McInerney 2008; Oliver and Montgomery 2008; Hardy and Maguire 2010; Möllering 2010; Zilber 2011; Schüßler et al. 2014). Originally developed in organizational institutionalism and management studies, the FCE approach refers to a rather broad spectrum of "temporary social organizations such as tradeshows, professional gatherings, technology contests, and business ceremonies" (Lampel and Meyer 2008: 1026). ${ }^{4} \mathrm{~A}$

\footnotetext{
${ }^{2}$ According to the International Congress and Convention Association, a 'conference' can be understood as a "participatory meeting designed for discussion, fact-finding, problem solving and consultation" (ICCA 2012b) with a limited time frame, organized around a specific topic or theme. The term 'business conference' as used here refers to a sub-type of conferences that involves representatives from different business organizations and revolves around presenting targeted information, sharing knowledge between peers and developing new knowledge (Hansen 2010).

${ }^{3}$ An overview of conference-related literature can be found in Lee and Back (2005) and Hansen (2010).

${ }^{4}$ According to Lampel and Meyer (2008), FCEs are characterized by six features: (i) They bring together actors from diverse backgrounds (professional, organizational and/or geographical); (ii) they are temporary in nature; (3) they provide opportunities for unstructured face-to-face interactions; (4) they include ceremonial and dramaturgical activities; (5) they provide occasions for information exchange and collective sense-making; and (6)
} 
central feature of FCEs is that they "have the potential, or even the explicit aim, of shaping a new market" (Möllering 2010: 10). Therefore, they are viewed as having a "substantive impact ... on the evolution of [their underlying] fields" (Lampel and Meyer 2008: 1028) or to be "turning points in the social, economic, and political transformation of our world" (Lampel and Meyer 2008: 1033f.).

As such, the FCE literature draws our attention to specific, individual events that fundamentally impact organizational fields. With respect to conferences, recent contributions provide significant insights in how firms may institutionalize their environments (Möllering 2011). Oliver and Montgomery (2008), for instance, show in their study of the one-day ' 11 th Congress of Jewish Lawyers', held in Palestine in 1944, how shared cognitions between the conference attendees were decisive for configuring the Israeli legal system and its surrounding policy context. Mobilizing these changes was highly planned and participants of the event came with the knowledge that they would fundamentally structure this bounded field. Another example is described by Hardy and Maguire (2010) in their study of a specific United Nations conference that resulted in the 'Stockholm Convention on Persistent Organic Pollutants'. They show that this conference generated - purposely and well-planned in advance - discursive spaces in which texts were produced, distributed and consumed. These spaces allowed participants to develop new narratives which, in turn, instigated significant changes in the underlying organizational field.

Both conferences had a strong policy focus and were orchestrated in advance by the organizers. Even though these examples demonstrate how FCEs can operate, international business conferences do not necessarily contribute in similar ways to field configuration. Möllering (2010), for example, shows for a conference on lithography technology in the semiconductor industry that the actual course of an event can change spontaneously, even though it may be "planned long in advance, with a binding agenda and ... significant organizational resources ... behind them and performances by participants that have been carefully planned" (Möllering 2011:31). In this specific case, the conference contributed to the ongoing reproduction of the respective organizational field but did not result in substantive, discontinuous field configuration. When considering the fact that "that not all conferences are full of evolving, dynamic, emerging, and developing processes only" (Hansen 2010: 254) but are often "selfpreserving, constantly re-establishing and negotiating the status quo" (ibid.), the FCE approach may be appropriate in the early development of a field but, as argued in this paper, does not characterize the conference business very well. Field configuration processes may play a substantial role in the context of specific policy fields, or when dealing with local or bounded fields characterized by a limited number of agents, mandates and relationships - but, as argued here, such processes may be difficult to achieve in large, open, international organizational fields or sub-fields that are characterized by myriads of individual agendas and decentralized actions and interactions of the different participants.

In more recent work, there has been a tendency in the FCE literature to also consider events with a "weak field mandate ... [that] influence field evolution indirectly, serving primarily as social networking hubs" (Lampel and Meyer 2008: 1028), as illustrated in the studies of Anand and Jones (2008), Hardy and Maguire (2010) and Schüßler et al. (2014). However, such an opening up of the FCE concept is problematic (Gibson and Bathelt 2014), as it leads to a situation where it becomes very difficult, if not impossible, to deny field-configuring

they create social and reputational resources which can be deployed in other contexts and for other purposes. However, as argued below, this definition is remarkably unspecific (Gibson and Bathelt 2014). 
character to any event. In this case, the concept becomes less meaningful and may lose its innovative character. ${ }^{5}$ The fact that a series of events, such as business conferences, gradually contribute to the ongoing structuration and reproduction of their underlying fields, is, however, a normal process that should be distinguished from the discontinuous impact of singular fieldconfiguring events.

In addition to the above limitations, the FCE concept has also methodological shortcomings, as stressed by Möllering (2011). It is, for example, impossible to determine ex ante, whether an event can be considered as field-configuring or not. The analysis of the fieldconfiguring character of a conference thus necessarily requires a retrospective approach. ${ }^{6}$ Furthermore, neither does the concept develop a methodology of how to include influences on a field that occur outside a specific event, nor does it analyze the structural components according to which some events may have a stronger field-configuring character than others. ${ }^{7}$

Given these criticisms, considerable doubts need to be raised as to whether the FCE concept can be usefully applied to study the general impact of international business conferences. As our case studies illustrate, conference organizers typically predefine certain topics and foci of their events primarily to stimulate ongoing interaction and high participation, but do not necessarily aim to direct or limit the participants' discussions and actions with regard to content. As such, business conferences normally do not end with one specific defining result, nor do their participants exercise dominant influence as a collective body. Rather, they provide manifold opportunities for face-to-face interaction that stimulate decentralized processes of knowledge circulation and sense-making. It is through such processes that conferences impact the reproduction of their respective fields and shape the institutional basis of their underlying knowing communities (Boland and Tenkasi 1995). ${ }^{8}$

\section{Business Conferences as Temporary Clusters}

By providing a conceptual link between temporary meetings and the permanent economic geographies of participating industries, the concept of the 'temporary cluster' adopts a different focus than the FCE approach. However, it provides a framework for analyzing the knowledge flows that occur during conferences and how they shape and reshape the development of communities, firms and organizational fields. As such, the concept can be used to investigate crucial knowledge circulation processes that impact the ongoing reproduction of fields. Organized professional gatherings, such as international trade fairs, establish an institutional basis for the meetings of industry representatives from a broad range of firms and organizations that operate in different regional and national environments, providing them with manifold

\footnotetext{
${ }^{5}$ In such a situation, other conceptual and methodological tools may be applicable that allow researchers to analyze how structure and agency influence each other in interdependent and often more incremental ways (i.e. drawing from structure-agency conceptions).

${ }^{6}$ This is the reason why Möllering (2011) correctly argues that the criteria suggested by Lampel and Meyer (2008) are not very helpful when trying to identify FCEs. In fact, almost any kind of event would fulfill these criteria (Gibson and Bathelt 2014).

${ }^{7}$ Another methodological shortcoming of the approach is that it refers to unclear cause-and-effect relations. In the literature, FCEs have been conceptualized both as products of a field and inputs to field structuration. Methods, such as network or discourse analysis, have not yet been employed to include the relevant macro structures of a field, which lie beyond single events (Möllering 2011).

${ }^{8}$ The concept of 'communities of knowing' or 'knowing communities', while originally applied to the corporate context (Boland and Tenkasi 1995), refers to mixtures of different communities of practice and epistemic communities that operate in, and are focused on, a specific knowledge context. It is thus well-suited to include the complex and multi-faceted knowledge creation practices that characterize an organizational field.
} 
opportunities to exchange knowledge about the business context and trends in their field (Maskell et al. 2006; Bathelt and Schuldt 2008; Rinallo and Golfetto 2011). The participants at these events are characterized by partly overlapping and complementary knowledge bases related to comparable educational backgrounds and/or job responsibilities, as well as similar day-to-day routines (Nooteboom 2000). They are part of specific knowing communities that can efficiently exchange and interpret knowledge along different dimensions (Cohendet et al. 2013). It is these knowledge flows and communication patterns that become important elements of the related field-reproduction and -structuration activities.

Whereas this concept has been primarily used to describe the interaction and communication processes at international trade fairs (Bathelt and Schuldt 2008; Gibson and Bathelt 2014), we suggest that it can be applied in similar ways to conceptualize the knowledge exchange processes during business conferences. As temporary clusters, business conferences, like trade fairs, provide opportunities for horizontal and vertical interactions and observations between members of the respective organizational fields (Bathelt and Henn 2014). In conversations and discussions at conferences, representatives of firms belonging to different or similar parts of value chains have the opportunity to exchange knowledge about trends, experiences and requirements for future products, services and innovations with suppliers and customers. This is most obvious in the trade fair component many conferences have, where specialized suppliers show their latest product and service offerings. Communicating in temporary spatial proximity bears significant advantages as it allows the involved agents to directly study emotion- and attention-related subjective and physiological responses of their counterparts, such as facial expressions, and to react accordingly (e.g. Short et al. 1976).

Yet, there are also important differences between different types of temporary clusters. While some conferences, similar to trade fairs, may be focused on particular industries and refer to their broader organizational field, most are different in that they revolve around pre-defined themes that change from event to event in correspondence with the dynamic changes in the underlying functional field. ${ }^{9}$ They revolve around topics and discussions and not around new products/technologies or their material representations in the form of exhibits. Although, as mentioned above, trade fair components may still exist in the hallways or halls of the conference center, the participants' primary focus is directed towards the conference sessions, presentations, discussions and the exchange of experiences around core topics in the respective fields (Bathelt and Henn 2014). For these reasons, conferences, more so than trade fairs, bring together specialized knowing communities of experts that have similar jobs, positions and responsibilities in their firms and organizations (Cohendet et al. 2013) and thus have different perspectives on the same subject. They develop around specific functional fields that sometimes have a crossindustry character.

As a consequence, the horizontal dimension becomes quite dominant for knowledge exchanges at conferences while the vertical dimension is often less important. Although trade fairs also bring together representatives of firms and organizations that are engaged in the same sets of activities and possibly directly compete with one another, these agents will likely not interact much at the fair but rather benefit from multiple opportunities to observe and systematically compare products and strategies with those of their rivals (Bathelt and Schuldt 2008). At conferences, in contrast, the participants often have the same or similar corporate

\footnotetext{
${ }^{9}$ The term 'functional field' refers to a sub-field that is part of an organizational field and, at the same time, connects different organizational fields along specific functional divisions, such as marketing, corporate governance or disaster management.
} 
functions and a similar focus in their work, yet competition may not be a dominant element during these events (Ichijo et al. 1998). In fact, direct interaction with other participants that share similar backgrounds and experiences are at the core of business conferences and foster open exchanges of knowledge.

Aside from these differences, another characteristic of business conferences needs to be emphasized that does not exist during trade fairs. Conferences are typically focused on key presentations of experts in the field, which reflect upon new relevant academic and/or professional findings and developments (Hansen 2010; Ravn and Elsborg 2011). These experts and their contributions become crucial reference points for the participants, around which discussions enfold. It is through the definition of conference topics, the selection of experts and other presenters, and the thematic organization of the conference sessions that organizers tend to have a more direct impact on conferences (Möllering 2011), compared to general industry fairs (Gibson and Bathelt 2014). While this generates field-configuring potential, the diverse actors that attend international business conferences have different motivations and are less likely to focus only on the externally decided, pre-defined themes (Möllering 2010). We are more likely to see many different topics and agendas at the center of highly-decentralized communications and knowledge exchanges at these events - and these may not even be key themes picked by the organizers.

In any case, business conferences define crucial meeting points through which important present and future changes in the respective functional field are circulated, discussed and evaluated among the underlying knowing communities. Open and broad exchanges between participants extend from conference sessions to brief hallway discussions, conversations at social events, lunch exchanges, and so on. In these contexts, not only are explicit knowledge components constantly contextualized and illustrated, but tacit knowledge elements are explicated to others and demonstrated in their relevance. The face-to-face conversations provide multiple social cues that are helpful in understanding complex knowledge bodies and translate conference findings into the different industry contexts of the participants (Short et al. 1976; Walther et al. 2005). It is the nature of these intensive face-to-face exchanges that enables collective processes of sense-making (Weick 2001) and serves to reduce risks and uncertainties in corresponding decision-making processes of the firms and organizations later on.

Related to the functional and cross-industry character of the field, the knowledge exchanges during conferences provide mechanisms for field reproduction at two levels. First, they actively drive the reproduction of the knowing communities that get together during the events. Attendees participate as self-selected members of these communities or as representatives of firms and organizations that are sent to these get-togethers. Second, since the community members are representatives of different firms and organizations across the field, conferences support the field's reproduction via processes of knowledge circulation. Due to ongoing interactions and observations during the events and their cyclical character (Power and Jansson 2008), business conferences help to establish contact networks and latent repositories of potential partners that can be activated in the future to provide access to different parts of and experiences in the fields

\section{Study Context and Methodology}

The empirical part of this study is based on an investigation of business conferences in Toronto. Due to its large size and role as a major air traffic hub, the city has become an important location for meetings and conventions in North America, characterized by a substantial growth in recent 
years. While Tourism Toronto and its partners reported 577 events in 2010 with 361,500 attendees, the numbers reported in 2013 were about 30 percent and 12 percent higher, respectively, with 745 events and an attendance of 406,000 (Tourism Toronto 2012; 2014). For the year 2011, Tourism Toronto disclosed more detailed information about 101 individual events that did not have the character of private meetings (i.e. not including closed membership meetings, secretive meetings or meetings for repeat business). Of these events, 18 were business conferences. About half had integrated trade fair components and all, except for one, took place in the downtown area.

In terms of conference infrastructure, the city of Toronto is well-equipped for hosting major events. It has two airports, which are connected to important national and international destinations, making it convenient for organizers and travelers to choose Toronto as a conference location. In addition, the city has 133 conference hotels, 51 of which in downtown locations, as well as four larger convention centers. Overall, the conference and convention business activity has become an important economic factor in the city, stabilizing employment in the tourism and hospitality sector, which accounted for 224,000 employees in the Greater Toronto Area (Tourism Toronto 2011). In 2011, conventions and trade shows held at the Metro Toronto Convention Centre alone generated an economic impact of \$523.7 million (CAD) (direct spending only), translating into 6,000 jobs and total tax revenues of about $\$ 177.5$ million (CAD) (MTCC 2012).

The empirical analysis in this paper focuses on three conferences held in 2012 that are among the leading such events in North America, or even globally: Microsoft Worldwide Partner Conference (WPC - a software sector conference), ISG Natural Resource Investing Summit (ISG - a resource-related investment conference) and World Conference on Disaster Management (WCDM - a business continuity and emergency management conference). From a larger group of conferences that we investigated and where we conducted interviews and observations, we selected these three in the context of this study because they covered the diverse spectrum of events encountered. As such, our approach draws from a most-differentcases strategy (Seawright and Gerring 2008). In particular, we chose events that covered different industries (ranging from the investment to the software sector), varied in size (between 290 and 5,000 attendees), represented different event types ${ }^{10}$ and took place at different types of locations (from hotel to convention center). The goal of our analysis was to focus on a small group of case studies that represent a large degree of variety among business conferences. While we do not claim representativeness in our study, this approach enables us to identify important commonalities and differences in a research field that has been widely neglected in the analysis of knowledge transfers and knowledge creation processes over distance (Bathelt and Henn 2014).

Our empirical analysis is based on interviews with two of the conference organizers and 30 attendees from diverse organizations, as well as on systematic observations conducted during all three events: 15 interviews at WPC, 9 at ISG and 8 at WCDM. Interviewees were selected to support and complement our observations. We approached participants over a period of two to three days, whenever there was an occasion (i.e. during a coffee or lunch break and between sessions) and when they did not appear to be in a rush. They were asked to reflect upon their experiences, interactions, the presentations they attended and the dynamics of the entire event. In most cases, conference participants were willing to take part in a short interview. Even though the interviews were held in the hallways, in front of the conference rooms and meeting spaces, on the exhibition floors or inside the lunch facilities, they were carried out without interruptions

${ }^{10}$ While ISG can be classified as a sales conference, WPC and WCDM are business conferences focused on discussions of common practices and problems. 
in an atmosphere that did not noticeably affect the response behavior. As the conferences addressed specific corporate divisions and functions, our interviewees were part of the respective knowing communities and primarily consisted of decision-makers in charge of specific sections or departments of the firms or organizations they represented.

The questions in our interview guide were organized according to different sections. They began by inquiring about the reasons for participating in and the purposes of the events. This enabled us to develop an understanding of the role of the conferences within their respective fields and their importance in relation to other conferences. In the main sections of our interviews, we systematically explored processes of horizontal and vertical knowledge exchanges and communications with different attendee groups during the events. We further asked questions about the roles of face-to-face contacts and the resulting learning processes, and inquired about relevant contacts made during the events. In the end, we asked for basic firm characteristics, such as sector and employment. Overall, our interviews were designed to be reasonably short and took about 15-20 minutes on average. Most conversations were digitally recorded and later transcribed. Our systematic observations focused on the types and circumstances of interactions between participants, their behaviors in response to others and in discussions, as well as their reactions and comments in listening to the presentations and in inspecting the exhibits.

\section{Knowledge Circulation and Field Reproduction at Business Conferences}

In the following sub-sections, we discuss each of the three conferences studied to identify their specific characteristics as temporary clusters and the field reproduction processes they support. Similar to the approach described in Bathelt and Henn (2014) to characterize configurations of knowledge transfers over distance, we analyze the knowledge circulation processes during these events by systematically discussing (i) the structure and goals of conferences, (ii) the types of attendees and knowing communities that meet and, importantly, (iii) the characteristics of faceto-face contacts and knowledge flows that occur. The discussion shows that international business conferences enable important knowledge circulation processes both across knowing communities and functional fields. We demonstrate how they contribute to the reproduction and gradual development of the institutional basis of their respective fields, rather than initiating fundamental changes to them.

\subsection{Microsoft Worldwide Partner Conference (WPC)}

(i) Structure and goal of the conference. WPC is an annual global conference that brings together a large variety of Microsoft partners - i.e. independent firms that offer Microsoft support as part of their portfolio of product/service offerings - to inform them about the latest products, software and cutting-edge technologies developed by Microsoft. WPC is the most important event for the Microsoft partner community and functions as a meeting point that enables interactions between different partners and between partners and Microsoft staff. Since 2003, the conference has been held in alternating venues in North America and took place in Toronto for the second time in 2012. It complements national-level partner meetings and is the largest event organized by the software producer. Compared to other conferences that focus on a single technological subsegment, this event addresses a broad spectrum of technologies and software solutions.

The five-day conference was held in the Metro Toronto Convention Centre and the Air Canada Centre in downtown Toronto. It consisted of more than 600 presentation sessions and 
involved renowned keynote speakers, amongst them Steve Ballmer, CEO of Microsoft, and Deepak Chopra, a global leader and pioneer in the field of mind-body medicine. The Toronto event specifically served as a platform for introducing Microsoft's new operating system Windows 8 . Additional foci of the event were Office 365 and cloud computing. The conference attracted more than 16,000 attendees from 156 countries, amongst them 4,391 first-time visitors (Fox 2012). It also included a trade show component with about 130 exhibitors from different areas related to information technologies. ${ }^{11}$

(ii) Attendees and knowing communities. The conference was open only to certified Microsoft partners. The representatives of these firms operate in different segments of the information technology sector but, due to their roles as partners, share a basic fundamental understanding of the software solutions offered by Microsoft. Having similar professional positions and experiences in a large variety of related areas (e.g. cloud computing), the attendees constituted diverse, yet overlapping knowing communities. Since participants often attended this conference on a regular basis, they got to know many peers and potential partners over time. Meeting these acquaintances again created some element of familiarity in a very large and otherwise anonymous setting.

(iii) Face-to-face interaction and knowledge flows. In many cases, it appeared that networking opportunities occurred randomly during WPC, e.g. when bumping into others after a session, during a coffee break or during manifold luncheons, cocktail parties and other social events. However, the conference organizer provided important technical support for participants that helped them to quickly find counterparts they would be interested in meeting. The attendees' name tags were, for example, printed in different colors allowing individuals to be recognized as members of specific groups. The tags also included barcodes, which - when being photographed with a smartphone - allowed participants to quickly access specific information about individual actors and their organizations. In addition, the conference offered manifold opportunities for systematic observations, to identify potential partners. One interviewee, for instance, described that he was interested in seeing to which sessions representatives of other firms would go to. This would allow him to identify peers in complementary business areas - an aspect which he would discuss with these individuals face-to-face after the sessions. Many of the interactions we encountered had primarily a horizontal, rather than a vertical character.

Interestingly, interviewees seemed especially interested in contacts with their fellow countrymen. The fact that they travelled to Toronto to enter in discussions with attendees from their home market, speaking the same language, clearly indicated the need for precise face-toface knowledge exchanges and evaluations without misunderstandings. The conference organizers supported such communications through the establishment of country-related lounges and program sections.

Often, the networking efforts at WPC did not seem to have an immediate impact on business activities, but rather provided firms with potential contacts that could become relevant in the future. Aside from making new contacts, co-presence also allowed attendees to meet with former contacts and partners to maintain existing relations. One copywriter from Germany emphasized that she had been working as an independent writer and marketing agent with Microsoft for a while, and that her business relationships had to be renewed and confirmed from

${ }^{11}$ Although this was the largest, broadest and most complex of the events investigated, it was also the most rigid and closed one in terms of controlling access to the facilities, sessions and specific events. As opposed to all other conferences, during which organizers allowed us to widely explore all sorts of sessions and get-togethers, we were quite limited in what we were allowed to do and where we were allowed to go at WPC. 
time to time. The fact that WPC gave her the opportunity through face-to-face conversations to bring herself back to the attention of Microsoft managers was the main incentive for her participation.

Even though the event included a comprehensive educational program, gaining new product-related knowledge often only appeared to be a secondary reason for attending. As one interviewee explained, this was due to the relatively broad focus of the event. In contrast to WPC, conferences with a narrow focus on specific sub-fields would offer more opportunities for product-specific knowledge exchanges. Against this background, it is not surprising that several interviewees expressed that they did not really expect major industry shifts to occur based on this conference. Rather, as one person stated, "[i]t is our job to know the innovations and present them to our clients ... It would be unusual for something to show up here which ... is not already on our radar" (translated from German). Instead, the participants were interested in sharing best practices and receiving updates on the latest market developments of new Microsoft products or on Microsoft's roadmap for the next years. Such information was relevant since it allowed the participants to develop expectations about Microsoft's plans, to align their businesses accordingly and to reflect upon their partnership with Microsoft. Interactions and observations also allowed the firms to compare themselves with their competitors. This provided important information for potential fine-tuning of product/service strategies after the conference. The knowledge acquired at WPC thus helped firms to develop ideas for incremental innovations later on and how to implement them.

Face-to-face communications played an important role for the acquisition of knowledge and took place in multiple ways and at different occasions. As expressed in almost all interviews, knowledge sharing was an essential part of the conversations. Especially informal settings like field trips, welcome receptions, common breakfasts and luncheons generated a relaxed atmosphere conducive to open knowledge circulation. Having opportunities for manifold knowledge exchanges with peers and "folks in similar positions" enabled attendees to better evaluate and interpret the quality of the knowledge they acquired. Facial expressions and body language would help comprehend the architecture of new solutions and emphasize crucial knowledge components, as described by one interviewee. Another interviewee from a large US software firm confirmed this by pointing out that people would be "more honest if you are face to face with them".

In addition to face-to-face interactions, observations provided the participants with important insights about current trends in the field as, for example, important conference topics helped to recognize or confirm latest technological and market developments. A manager of a London-based web 2.0 security firm described this in the following way:

"You grasp something just by being there. You come to know about trends, you get a feeling which seminars are attended by more people. Which topics does nobody go to? What are the themes that motivate others? I, for example, observe that hosting $\mathrm{B} 2 \mathrm{~B}$, which was less dealt with in prior conferences, is a distinct subject here and that the sessions about this topic are also in vogue" (translated from German).

Having such observations in mind allowed the manager to draw conclusions about the development of the market. A well-attended session about how to best market a specific new technology was interpreted by him as an indication that this technology was about to leave its stage of infancy and enter broader markets. 
To sum up, even though WPC was a very large, well-organized and hierarchicallyplanned conference, it aimed at presenting and marketing new software products rather than generating a "shift in [the] order" (Garud 2008: 1084) of the underlying organizational field. As such, this conference did not have field-configuring character. It rather aimed at the reproduction of the field by allowing firms to establish new contacts with potential business partners and/or to maintain existing contacts. The large variety of horizontal interactions provided attendees with opportunities to compare themselves with competitors and peers, to acquire information about market trends and to evaluate the quality of these updates. Incremental updates of their knowledge bases allowed attendees to adopt changes in strategies and to implement new software solutions for the changing market and technology context.

\subsection{ISG Natural Resource Investing Summit (ISG)}

(i) Structure and goal of the conference. This three-day natural resource investment conference took place in the Fairmont Royal York Hotel, a luxurious conference hotel in downtown Toronto. The conference brought together two types of attendees: potential investors and those hoping to attract an investment (referred to as offerers). From the point of view of the investors, the aim of ISG was to gain specific knowledge about investing in natural-resource-based and commoditiesoriented businesses. From the point of view of the offerers, the goal was to attract the attention of people interested in resource-based investments. The event attracted about 290 participants, half of them from Ontario and the other half from other regions in North America. At the center were 21 offerers who presented themselves on a small exhibition floor as potential investment targets, most of them early-stage exploration and mining firms, but also one publishing firm. The conference took place for the very first time in 2012 and, as a consequence, was not (yet) considered to be a leading event. As a financially-oriented conference associated with natural resources, the idea behind ISG was to complement the more technically-oriented, much larger annual convention of the Prospectors \& Developers Association of Canada (PDAC) that also takes place in Toronto.

(ii) Attendees and knowing communities. The conference was attended by individuals belonging to different interrelated knowing communities. This included two types of investors: A first group consisted of individual investors who, according to one of the sponsors of the conference, had "a lot of disposable income for investing" and were looking for information about recent developments in the natural resource sector and how to best invest in it. Many of these individuals were clients of the conference organizer, an investment advisor firm. They knew several of the other investors from former similar events. As one of the representatives of the organizing firm explained to us, 120 attendees were clients of an independent wealth management firm that consults wealthy individuals and presents investment opportunities to them. Not all were immediately interested in finding investment targets in the natural resource sector, but aimed at deepening their knowledge and expertise in the field. Through ongoing interactions with their peers at the conference, they formed what could be described as a community of practice (e.g. Wenger 1998).

A second group consisted of representatives of investment firms that had been, as one organizer explained, on the market for five to ten years. They were selected and invited by the organizer of the conference because they were considered to be amongst the most promising firms in the field. The main goal of these firms was to present themselves to potential clients (offerers). The managers of the investment firms shared a similar work experience. They were interested in becoming new shareholders and kept interacting with each other during the conference, constituting another community of practice. According to our interviews, some 
representatives of these investment firms already knew each other well from the past and had a friendly relationship, as they held mutual shares in the same client firms. They formed a "shareholder brotherhood" as the director of investment relations of one of the mining firms called it.

The fact that many of the individual investors and the investment firm managers were geologists, engineers or industry professionals also reduced the cognitive distance between them and the offerers, providing ideal grounds for efficient knowledge exchanges.

(iii) Face-to-face interaction and knowledge flows. In order to better understand the knowledge flows and the role of spatial proximity at ISG, it is necessary to take a closer look at the respective industry context. The participating offerers seeking for investors were early-stage mining firms. According to one observer, it takes about 5-10 years before investments in these firms pay off, and many firms never make major discoveries, nor do they ever move into the production/exploitation stage. Therefore, investments are associated with very high risks for the investors. In order to reduce these risks, potential investors collect as much knowledge about the offerers as possible. Since crucial knowledge components cannot be distributed in codified form alone, for instance through written brochures, it is crucial to communicate face-to-face with the offerers about potential projects and future prospects. This is because, as one manager of investor relations emphasized, "it is still about people looking into the eye" and providing straightforward information about all details of the respective investment projects.

The main goal of the offerers was to increase investor awareness. To reach this goal, the offerers gave 40-minute presentations about the type of operations they were planning, the management of the firm and financial aspects. During these sessions, the participants were allowed to ask questions and collectively received important insights into the different investment contexts. The sessions were followed by coffee or lunch breaks, which gave attendees the opportunity of exchanging ideas with the presenters. Such conversations were conducted around tables or at the booths of the offerers. The offerers benefitted from this because they received clear ideas of what a potential investor would expect from them and how market developments were evaluated.

Aside from the conference sessions, ISG also included informal events, such as a reception and a cocktail party, which created a relaxed atmosphere for additional vertical and horizontal knowledge exchanges and provided opportunities to follow up details. Investors used the opportunities to approach the offerers and ask further questions, which they did not want to share with their peer investors. It was emphasized during the interviews that direct meetings between the potential investors and the offerers were key for the establishment of some initial, albeit limited, trust as a basis for the development of personal relationships in the future.

Face-to-face communications at ISG allowed the attendees to discuss the contents of the presentations with peers and engage in collective sense-making. One investment advisor described, for example, how one of her clients asked for her opinion: "They come up to me and they say: ... we have been talking ... about this and that, but I just listened to one speaker ... You think ... that what he said is going to be actually translating into things?" Such short exchanges supported the evaluation of project ideas and helped distinguish projects with acceptable from projects with inacceptable risks. Offerers viewed these interactions as a preparation for future meetings with potential investors. Knowledge exchanges also helped the offerers to draw conclusions about the reliability of potential investors and their statements. This was important to avoid false expectations and a sudden and unexpected withdrawal of investments with damaging effects. 
Aside from vertical interactions, the conference was characterized by manifold horizontal knowledge flows that were equally important and also supported collective sense-making. Even though the offerers were competing for potential investment targets, they did not regard others as "competitors that we fight with", as one investor emphasized. Rather, the investment firms viewed each other as sitting in the "same boat", thereby alluding to the fact that if their rivals succeeded, this would be beneficial for the community and the sector overall. Therefore, investors were actively engaged in forming network relations with each other, which would allow them to exchange business-related knowledge. As one interviewee put it, "[w]e know each other, so we are always talking, and picking up new ideas or picking up nuggets of information ... That is very important for us." It should also be mentioned that the offerers seeking investments often had a business focus in different markets and were thus only partial competitors. This aspect appeared to be important because it enabled knowledge crossfertilization, as explained by one sponsor of the conference:

"A company that has a special expertise in a type of terrain you will see in Western Canada may have special knowledge to offer to a company that is used to explore in

Northern Ontario but gets a property in Peru. The property in Peru will be more similar to the properties that they will see in Vancouver or Alaska. So, in that case, the Ontario company may access the technical expertise of its competitor."

Face-to-face discussions amongst the representatives of the firms, both horizontally and vertically, thus resulted in important knowledge exchanges about best practices and market conditions. However, similarly important were the interactions between the participants and the primary conference sponsor - an individual, who was considered to be one of the top 50 US investment bankers in the oil and gas business and whom many interviewees regarded as an outstanding authority. It was striking to observe how he was constantly surrounded by other investors engaging in group discussions, even while presentations were going on.

To sum up, ISG served as a platform for face-to-face conversations between investors and offerers. Vertical and horizontal interactions provided important steps in creating new investment bonds, for sharing best practices amongst peers and competitors and for acquiring incremental updates about the current state of the industry. For early-stage resource extraction firms, an important conference result was to receive feedback from potential investors about their strategies, which was important in furthering corporate strategies. Unlike a FCE, ISG thus did not have a major impact on the underlying field but rather contributed to a gradual development of new investor-offerer relations in a dynamic resource exploitation context.

\subsection{World Conference on Disaster Management (WCDM)}

(i) Structure and goal of the conference. WCDM is an annual conference that covers a wide range of topics in the areas of disaster, risk and emergency management for firms and organizations from different sectors. It is the most important conference of this type in North America and, due to its size, breadth and diversity, can be considered as a leading event in this field. Since its establishment in 1991, WCDM has been organized in different venues throughout Ontario with stable attendance levels over the years. In 2012, the three-day event took place in the Metro Toronto Convention Center in downtown Toronto and attracted about 1,100 emergency managers and other individuals interested in and engaged with the preparation for, response to, and mitigation of disasters and emergency situations. According to the conference organizers, only about 30 percent of participants originated from within Canada, another 40 percent from the US and the remaining 30 percent from overseas. The share of foreign participants is higher than that at similar conferences in the US, indicating the importance of 
WCDM at an international and even global scale. Most attendees were representatives of larger firms and organizations with multiple locations. One of these firms had 140,000 employees in North America alone. The conference included 86 sessions, numerous social events such as a gala awards dinner and a speakers' reception, as well as a trade show component with 37 exhibitors.

(ii) Attendees and knowing communities. WCDM is a prime example of a business conference that is focused on a functional field, i.e. business continuity, disaster and emergency management. It attracts attendees from a large variety of different industries, ranging from banking through manufacturing and public services. Many participants of WCDM had similar positions in their firms and organizations and thus shared similar organizational experiences. As disaster and emergency managers, they were often regarded as inconvenient outsiders in their organizations. Because of this organizational pressure, they formed a closely-knit community of practice, which was visible at WCDM. It seemed that attendees typically knew numerous other participants suggesting that linkages amongst them were characterized by some relational proximity, in addition to their cognitive proximity.

(iii) Face-to-face interaction and knowledge flows. The main reason for participants to attend this conference was to acquire new knowledge in the field that was viewed as important in order to minimize disruptions in production and to make the work environment a safer and less dangerous place. Participants were also interested in evaluating what new discussions were developing and which practices were being introduced in reaction to new challenges. This allowed them to compare their organizations with others and get a sense of where they were positioned within the industry.

Important knowledge was circulated during the series of presentations, especially those given by well-known speakers and experts with profound experience in the field. They brought certain issues to the forefront and set the tone for discussions. These expert presentations and evaluations were, according to our interviewees, a "must-go". Overall, however, it appeared that the sessions played only a secondary role for many attendees. One North American business continuity manager insisted that it was more important "having the interactions [with peers] than just going to the sessions". Such peer interactions with prior and new acquaintances took place during coffee breaks and over lunch, at the end of sessions or during some of the social events. Sometimes, brief exchanges were even possible during special sessions, where the participants were situated around round tables.

The fact that WCDM attracted participants from many parts of the world, as well as from many different industry contexts, provided the attendees with broad opportunities of "coupling ideas and putting plans together" and thus of learning from experiences in other sectors, as one interviewees stated. In some cases, participants described how this triggered ideas they had not had before. In other cases, new ideas were generated through observations. One manager of a large US software firm stated, for example, that sellers who would meet a "multitude [of] people asking for the same thing should think that [they] should improve [their] products" in order to meet the customers' wishes. In general, participating in the knowledge flows provided the attendees with "lots of little nuggets" that had to be integrated into the larger picture to make sense. In some cases, however, the attendees' interests were much more specific as they were systematically looking for specific procedural know-how or problem solutions. A couple of interviewees, for example, stated that they were at the conference because they expected to meet with or listen to experts, who could inform them about a new standard that had been introduced 
just before the conference. Yet, little was known about this standard at the conference and no sessions were offered that dealt with related issues.

There were at least two reasons that made it easy to share knowledge amongst the attendees at WCDM: First, the knowledge components at stake were "taken from real life situations", as one interviewee explained, which meant that the themes presented were directly relevant and could be related to the participants' experiences. Second, as the attendees had a similar professional status and applied the same terminology in their daily work routines, they used a common language and did not have to explain the context, in which they operated, at length.

Although a large variety of sectors were represented at WCDM, exchanges of knowledge and best practices also took place between attendees that worked for direct competitors. One US manager explained the reason for this emphasizing that "there are no trade secrets in this community. The companies have to protect how we do our jobs. We only help each other by sharing information". In fact, since some participants "have changed jobs, done different things in different industries", sometimes "probably worked together in the past" and now are "doing the same work in different companies, or different fields, departments", a great sense of solidarity had developed amongst them. This was clearly strengthened because of their image as outsiders and potential trouble-makers within their organizations. As a consequence, the attendees indicated that they did not regard themselves as working for rivals, but rather viewed each other as "coopetitors", or as part of a "community of peers" that "transcends the competitive nature". This strong sense of solidarity and community membership created a general atmosphere in which knowledge was willingly shared with newcomers. One business continuity manager expressed this as follows: "I want to see them grow. I feel that is me paying back to the larger community by participating in that". By providing newcomers with experience-based knowledge in the field, agents were actively engaged in reproducing their community over time. According to the interviewees, sharing knowledge at WCDM was nurtured by a specific atmosphere that is generally "more about the spirit of sharing information". This atmosphere was characterized as being quite different from that during a trade fair. According to one business continuity and resilience services manager, the conference atmosphere is "not as pressing ... It is about really listening to the person on the other side of the table in an informal way".

Networking opportunities within the community were consequently an important reason to attend WCDM. While networks between individuals often seemed to evolve with a certain chance element, participants also made systematic new contacts, for instance by approaching the speakers after their presentations in order to receive further information about a particular issue or about ideas for solving a problem. In addition, as one firm representative in the conference exhibition explained, clients at the event acted as contact brokers: "Often customers will come to us, say: You do this and [another] partner does that - you should get together and have a conversation". Similar to the Microsoft conference, participants were also interested in meeting people with a certain expertise in order to have a potential contact person "someday when I need to".

Overall, WCDM created a temporary hub for sharing experiences and exchanging knowledge in the area of business continuity and disaster management for global members of this functional field. Open knowledge exchanges were facilitated by a strong sense of solidarity and community membership amongst the attendees. The conference clearly did not end up with one or few specific results and conclusions, as could have been expected from a FCE, but 
provided participants with myriads of incremental pieces of knowledge, which allowed them to adjust organizational practices and prepare for unexpected events. WCDM thus actively contributed to the reproduction of the respective field and its knowing communities.

\section{Conclusion}

This paper suggests that the concept of the 'temporary cluster' provides an appropriate methodological basis when analyzing the knowledge ecologies of business conferences and their impacts on the underlying organizational or functional fields. As temporary clusters, conferences bring together agents with similar qualifications and skills, as well as agents with different qualifications but working in similar functions, providing manifold opportunities for horizontal and vertical interactions and observations. Due to their business focus, specialization and technology, the participants share cognitive proximity (Nooteboom 2000) and establish specific knowing communities (Boland and Tenkasi 1995; Amin and Cohendet 2004) that have in-depth background knowledge of the topics presented or discussed at various occasions during a business conference. As a consequence, the attendees can efficiently exchange and interpret knowledge, learn across industrial/sectoral contexts, and create new knowledge. Business conferences can therefore be understood as platforms "for sharing mental models, coordinating activities and interacting to produce relationships" (Weick 2001: 95) amongst the participants and, thus, for enabling processes of collective sense-making.

This understanding has been substantiated through case studies of three international business conferences in different industries in Toronto. The results of our empirical investigations suggest that conferences support incremental innovations through different channels. Presentations held by internationally-renowned experts, informal conversations, as well as discussions with peers, and systematic observations are amongst the most important mechanisms for obtaining and evaluating new knowledge and updating existing knowledge. From highly decentralized vertical and horizontal knowledge flows, firms taking part in conferences can develop a better understanding of their positions in corresponding organizational fields or sub-fields. By applying these insights to their individual firm backgrounds, they can realign themselves to current developments thereby, in turn, affecting the underlying field through their actions and interactions.

All of these findings call for a more nuanced understanding of business conferences. While such events may sometimes create shared understandings plausible enough to motivate groups of attendees to engage in joint actions (e.g. Oliver and Montgomery 2008), as implied by the FCE approach, our study clearly points to the fact that conferences usually do not trigger disruptive changes of a particular field. They are rather characterized by highly-decentralized sense-making processes that, when applied to individual organizational contexts around the world, lead to ongoing reproduction of the respective fields and sub-fields.

In this context, the concept of the 'temporary cluster' provides an adequate framework to study important knowledge circulation processes with field-reproducing character that help understand the interrelationships between specific events and their underlying permanent geographies and field structures. Nonetheless, there is a need for further research on business conferences as temporary clusters. In particular, future studies need to elaborate whether different types of conferences in different national-institutional contexts vary in terms of primary learning mechanisms and under which conditions a conference can become a true FCE. It would also be important to investigate series of conferences to better understand how knowledge generation processes beyond single events contribute to the dynamics of organizational fields 
and sub-fields. Finally, it is necessary to understand how firms apply the knowledge acquired at conferences to their day-to-day business, thereby bringing about gradual changes to their respective fields and sub-fields - thus practicing knowledge transfer and creation over distance. In this context, it be may be interesting to investigate how different types of events, such as conferences and trade fairs, share elements of each other and create overlapping relational spaces.

\section{Acknowledgements}

This paper, to which both authors contributed equally, was presented at the 2013 Annual Meeting of the Association of American Geographers in Los Angeles. We wish to thank the participants of the sessions for providing supportive feedback and Oliver Ibert, Sufyan Katariwala and Joachim Thiel for valuable suggestions that helped sharpen our arguments. Funding for this research was provided by the Canada Research Chair in Innovation and Governance at the University of Toronto.

\section{References}

Amin, A. and Cohendet, P. (2004), Architectures of Knowledge: Firms, Capabilities, and Communities (Oxford: Oxford University Press).

Anand, N. and Jones, B. C. (2008), 'Tournament rituals, category dynamics, and field configuration', Journal of Management Studies, 45, 1036-1060.

Asheim, B., Coenen, L. and Vang, J. (2007), 'Face-to-face, buzz, and knowledge bases: Sociospatial implications for learning, innovation, and innovation policy', Environment and Planning C, 25, 655-670.

Bathelt, H. and Glückler, J. (2011), The Relational Economy. Geographies of Knowing and Learning (Oxford: Oxford University Press).

Bathelt, H. and Henn, S. (2014), 'The geographies of knowledge transfers over distance: Toward a typology', Environment and Planning A, 46, 1403-1424.

Bathelt, H. and Schuldt, N. (2008), 'Between luminaires and meat grinders: International trade fairs as temporary clusters', Regional Studies, 42, 853-868.

Boland, R. J. and Tenkasi, R. V. (1995), 'Perspective making and perspective taking in communities of knowing', Organization Science, 6, 350-372.

City of Toronto (2007), Making Toronto the Best it Can Be, Brochure (Toronto: City of Toronto).

Cohendet, P., Héraud, J.-A. and Llerena, P. (2013), 'A microeconomic approach of the dynamics of creation', in P. Meusburger, J. Glückler, and M. el Meskioui (eds.), Knowledge and Economy. Klaus Tschira Symposia: Knowledge and Space, Vol. 5 (Berlin: Springer), $43-$ 59.

Davidson, R. and Rogers, T. (2006), Marketing Destinations and Venues for Conferences, Conventions and Business Events (Oxford: Elsevier Science).

Davidson, R., Alford, P. and Seaton, T. (2002), 'The use of information and communication technology by the European meetings, incentives, conferences, and exhibitions (MICE) sectors', Journal of Convention and Exhibition Management, 4, 17-36.

DiMaggio, P. J. and Powell, W. W. (1983), 'The iron cage revisited: Institutional isomorphism and collective rationality in organizational fields', American Sociological Review, 48, 147-160.

Fox, A. (2012), Partner Perspective on Worldwide Partner Conference Day 1, Web report (Toronto), URL: http://www.digitalwpc.com/Community/Perspectives/Pages/PartnerPerspective-on-WPC-Day-1.aspx\#fbid=SL9FpA4ITNX (October 10, 2010). 
Garud, R. (2008), 'Conferences as venues for the configuration of emerging organizational fields: The case of cochlear implants', Journal of Management Studies, 45, 1061-1088.

Gibson, R. and Bathelt, H. (2014), 'Field configuration or field reproduction? The dynamics of global trade fair cycles', Zeitschrift für Wirtschaftsgeographie, 58, forthcoming.

Grabher, G. (2004), 'Temporary architectures of learning: Knowledge governance in project ecologies', Organization Studies, 25, 1491-1514.

Grabher, G. and Ibert, O. (2011), 'Project ecologies: A contextual view on temporary organizations', in P. W. G. Morris, J. K. Pinot and J. Söderlund (eds.), The Oxford Handbook of Project Management (Oxford: Oxford University Press), 175-198.

Grado, S. C., Strauss, C. H. and Lord, B. E. (1997), 'Economic impacts of conferences and conventions', Journal of Convention and Exhibition Management, 1, 19-33.

Hansen, N. J. (2010), Conferences as Dramaturgical Learning Spaces (Aarhus: Doctoral School of Organizational Learning (DOCSOL), Danish School of Education Aarhus University).

Hardy, C. and Maguire, S. (2010), 'Discourse, field-configuring events, and change in organizations and institutional fields: Narratives of DDT and the Stockholm Convention', Academy of Management Journal, 53, 1365-1392.

ICCA [International Congress and Convention Association] (2012a), The International Association Meetings Market 2002-2011. Abstract for International Associations, Press, Universities, Students and Consultants (Amsterdam: ICCA).

ICCA (2012b), What is the difference between a congress and a conference? (Amsterdam), URL: http://www.iccaworld.com/aeps/aeitem.cfm?aeid=909 (September 22, 2014).

Kim, B. P., Kim, D. and Weaver, P. A. (2010), 'An exploratory study of local organizations' conference choice factors', Journal of Hospitality Marketing and Management, 19, 503 513.

Lampel, J. and Meyer, A. D. (2008), 'Field-configuring events as structuring mechanisms: How conferences, ceremonies, and trade shows constitute new technologies, industries, and markets', Journal of Management Studies, 45, 1025-1035.

Lee, M. J. and Back, K.-J. (2005), 'A review of convention and meeting management research 1990-2003', Journal of Convention and Event Tourism, 7, 1-20.

Maskell, P., Bathelt, H. and Malmberg, A. (2006), 'Building global knowledge pipelines: The role of temporary clusters', European Planning Studies, 14, 997-1013.

McInerney, B. (2008), 'Showdown at Kykuit: Field-configuring events as loci for conventionalizing accounts', Journal of Management Studies, 45, 1089-1116.

Meyer, A. D., Gaba, V. and Colwell, K. A. (2005), 'Organizing far from equilibrium: Nonlinear change in organizational fields', Organization Science, 16, 456-473.

Möllering, G. (2010), Collective Market-Making at an Engineering Conference, MPIfG Discussion Paper, 10/2 (Cologne: Max-Planck-Institut für Gesellschaftsforschung).

Möllering, G. (2011), 'Umweltbeeinflussung durch Events? Institutionalisierungsarbeit und feldkonfigurierende Veranstaltungen in organisationalen Feldern', Zeitschrift für betriebswirtschaftliche Forschung, 63, 458-484.

MTCC [Metro Toronto Convention Centre] (2012), The Metro Toronto Convention Centre Generates \$4.7 Billion in Economic Impact to the Community Over the Past 27 Years, Press release (Toronto), URL: http://www.mtccc.com/news/detail.aspx?Id=66 (December 1, 2014).

Nooteboom, B. (2000), Learning and Innovation in Organizations and Economies (Oxford: Oxford University Press). 
Norcliffe, G. and Rendace, O. (2003), 'New geographies of comic book production in North America: The new artisans, distancing, and the periodic social economy', Economic Geography, 79, 241-273.

Oliver, A. L. and Montgomery, K. (2008), 'Using field-configuring events for sense-making: A cognitive network approach', Journal of Management Studies, 45, 1147-1167.

Oppermann, M. and Chon, K. S. (1997), 'Convention participation decision-making process', Annals of Tourism Research, 24, 178-191.

Power, D. and Jansson, J. (2008), 'Cyclical clusters in global circuits: Overlapping spaces in furniture trade fairs', Economic Geography, 84, 423-448.

Randall, J. E. and Warf, B. (1996), 'Economic impacts of AAG conferences', The Professional Geographer, 48, 272-284.

Ravn, I. and Elsborg, S. (2011), 'Facilitating learning at conferences', Journal of Learning and Change, 5, 84-98.

Rinallo, D. and Golfetto, F. (2011), 'Exploring the knowledge strategies of temporary cluster organizers: A longitudinal study of the EU fabric industry trade shows (1986-2006)', Economic Geography, 87, 453-476.

Rogers, T. (2008), Conferences and Conventions: A Global Industry (Oxford: ButterworthHeinemann).

Scott, W. R. (1994), 'Conceptualizing organizational fields: Linking organizations and societal systems', in H.-U. Derlin, U. Gerhardt and F. Scharpf (eds.), Systemrationalität und Partialinteresse (Baden-Baden: Nomos), 203-221.

Schlentrich, U. A. (2008), 'The MICE industry: Meetings, incentives, conventions, and exhibitions', in R. C. Wood and B. Brotherton (eds.), The SAGE Handbook of Hospitality Management (London: Sage), 400-421.

Schüßler, E., Rüling, C. C. and Wittneben, B. (2014), 'On melting summits: The limitations of field-configuring events as catalysts of change in transnational climate policy', Academy of Management Journal, 57, 140-171.

Seawright, J. and Gerring, J. (2008), 'Case selection techniques in case study research: A menu of qualitative and quantitative options', Political Research Quarterly, 61, 294-308.

Short, J., Williams, E. and Christie, B. (1976), The Social Psychology of Telecommunications (New York: Wiley).

Simerly, R. G. (1990), Planning and Marketing Conferences and Workshops: Tips, Tools, and Techniques (San Francisco: Jossey-Bass).

Tourism Toronto (2011), Microsoft Chooses Toronto for 2012 Worldwide Partner Conference. 15,000 People from 130 Countries Expected for Prestigious Conference in Toronto. Press release, July 13 (Toronto), URL:

http://www.seetorontonow.com/Media/MediaPressReleases/PressReleases-

MicrosoftWorldwide2012.aspx (March 25, 2014).

Tourism Toronto (2012), Meetings and Conventions Hosted in 2011 (Toronto), URL: http://www.seetorontonow.com/getattachment/041 ff268-a7be-4f66-84b13bf5759b1a6a/Meetings---Conventions.pdf.aspx (March 25, 2014).

Tourism Toronto (2014), International Visitors Lead Toronto to New Tourism Records. Press release (Toronto), URL: http://www.seetorontonow.com/getattachment/72a0332e-a6a64c81-9b44-2cd4e35c05e1/New-Tourism-Records-for-Toronto-in-2013.pdf.aspx (March $25,2014)$. 
Ichijo, K., van Krogh, G. and Nonaka, I. (1998), 'Knowledge enablers', in G. van Krogh, J. Roos and D. Kleine (eds.), Knowing in Firms: Understanding, Managing and Measuring Knowledge (London: Sage), 173-203.

Walther, J. B., Loh, T. and Granka, L. (2005), 'Let me count the ways: The interchange of verbal and nonverbal cues in computer-mediated and face-to-face affinity', Journal of Language and Social Psychology, 24, 36-65.

Wenger, E. (1998), Communities of Practice: Learning, Meaning, and Identity (Cambridge: Cambridge University Press).

Weick, K. E. (2001), Making Sense of the Organization (Oxford: Blackwell Business).

West, L. A. and Upchurch, R. S. (2001), 'Conference participants' acceptance of the Internet as an information and registration tool', Journal of Convention and Exhibition Management, $3,41-52$.

Zhang, H. Q., Leunga, V. and Qub, H. (2007), 'A refined model of factors affecting convention participation decision-making', Tourism Management, 28, 1123-1127.

Zilber, T. B. (2011), 'Institutional multiplicity in practice: A tale of two high-tech conferences in Israel', Organization Science, 22, 1539-1559. 